\title{
STUDY OF TEXTURAL, CHEMICAL, COLOR AND SENSORY PROPERTIES OF ORGANIC BLUEBERRIES HARVESTED IN TWO DISTINCT YEARS: A CHEMOMETRIC APPROACH
}

\author{
ALICE VILELA ${ }^{1,6}$, BERTA GONÇALVES ${ }^{2}$, CARLOS RIBEIRO ${ }^{3}$, ANA TERESA FONSECA ${ }^{4}$, SOFIA CORREIA ${ }^{2}$, \\ HORTENSE FERNANDES ${ }^{4}$, SÓNIA FERREIRA ${ }^{4}$, EUNICE BACELAR ${ }^{2}$ and ANA PAULA SILVA ${ }^{5}$ \\ ${ }^{1}$ Department of Biology and Environment, University of Trás-os-Montes and Alto Douro, Chemistry Research Center, UTAD, P-5000 801 Vila Real, \\ Portugal \\ ${ }^{2}$ Department of Biology and Environment, University of Trás-os-Montes and Alto Douro, Centre for the Research and Technology of \\ Agro-Environmental and Biological Sciences (CITAB), Vila Real, Portugal \\ ${ }^{3}$ Department of Agronomy, University of Trás-os-Montes and Alto Douro, Vila Real, Portugal \\ ${ }^{4}$ BioBaga, Rue Joue les Tours, Santa Maria da Feira, Portugal \\ ${ }^{5}$ Department of Agronomy, University of Trás-os-Montes and Alto Douro, Centre for the Research and Technology of Agro-Environmental and \\ Biological Sciences (CITAB), Vila Real, Portugal
}

\section{KEYWORDS}

Blueberries, Duke, Legacy, Camellia and Palmetto, harvest year, sensory and textural characterization

${ }^{6}$ Corresponding author.

TEL: (+351) 259350 592;

FAX: (+351) 259350480

EMAIL: avimoura@utad.pt

Received for Publication June 11, 2015

Accepted for Publication December 28, 2015

Published online Article Accepted on

February 10, 2016

doi:10.1111/jtxs.12173

\section{ABSTRACT}

In Portugal, two groups of blueberry plants are of interest: the Northern and the Southern Highbush Blueberry. The short season and short shelf life of blueberries yields excess fruit, and those harvests not destined for the fresh market are frozen or processed, sometimes leading to economic losses for the producers. From a technological point of view, fruit characterization is performed on the basis of physical, chemical properties as well as organoleptic properties (texture, flavor, color/pigmentation). These properties are directly correlated with fruit utilization. Thus, in this work, chemometric tools, such as texture, soluble solids (SS), titratable acidity (TA), fruit surface color and a trained sensory panel, for the exploration of textural, chemical, color and sensory characteristics of four blueberry cultivars harvested in two different years were applied.

Surface color, maximum force, SS, TA and SS/TA ratio varied among cultivars and years and, in general, all the fruits presented in 2013 had lower values for SS and TA when compared with those collected in 2011.

After analyzing all the parameters and independently of their origin, Duke and Palmetto seem to be more suitable for fresh market consumption since the attribute crispness did not change significantly between the 2 years, while Camellia, a cultivar where the attribute crispness, seems to be weather dependent, and Legacy a cultivar with less odor and flavor, seems to be more suitable for processing into products such juice and jam.

\section{PRACTICAL APPLICATIONS}

Blueberry is a product of interest due to their nutritional and health benefits. Recently, scientists have determined that is the "blueberry-like flavor intensity" the eating quality that has a much higher correlation to consumer acceptance than the traditional measures of sweetness, acidity or sugar/acid. Ripeness and maturity are the key factors that influence the taste of a fruit. Ripening processes play a key role in flavor development and can affect the chemical and sensory characteristics (acidity, sweetness) of fruits. Thus, with this study we can understand the influence of the harvest year in the textural and sensory attributes of blueberry fruits that can help to determine the optimal use of fruit. 


\section{INTRODUCTION}

Nowadays, the term "quality" is one of the most widespread keywords used in commercial trade. Nevertheless, product quality can assume different meanings for consumers, producers and regulating organizations. In the case of blueberries, quality may result from factors like the production system and the climate conditions of harvest year (Litz 2005).

Blueberry is a product of interest due to their nutritional and health benefits (Paredes-López et al. 2010). Blueberries are bushy plants belonging to the Vaccinium genus (Litz 2005). The fruit is a berry of color ranging from dark blue to black, round or slightly flattened, that can have more than one $\mathrm{cm}$ of diameter and a weight of 2-5 g (Oliveira and Fonseca 2010) Differences in cultivar, environment and handling methods can result in a range of flavor and texture profiles. For the Portuguese soil-climatic conditions two groups of plants are of interest: the Northern Highbush Blueberry (NHB) and the Southern Highbush Blueberry (SHB) (Oliveira and Fonseca 2010). Examples of NHB are the cultivars Duke and Legacy. Duke's mild flavor improves with cold storage and Legacy has received good reviews for its fruit quality, small scar and flavor. Palmetto is an early season SHB cultivar. Berries are firm, medium sized and are very flavorful (Nesmith et al. 2004). Camellia is a hybrid containing mostly Vaccinium corymbosum and a small amount of Vaccinium darrowi, is also a new midseason SHB cultivar whose berry firmness and flavor are very good (Nesmith and Draper 2006). The short season and short shelf life of blueberries yield excess fruit, and those harvests not destined for the fresh market are either frozen, processed into juices and canned products, or dried into a variety of products (Pallas et al. 2013). Sensory evaluation has played a key role of any product that is to be consumed by humans (Sidel and Stone 1993). This evaluation is useful in improving the value of the production and informing the consumers of the fruit quality at harvest, storage and shelf life (Mellano et al. 2009). Typical qualities or sensory attributes that are evaluated for blueberries include firmness, juiciness or succulence and color. The firmness of blueberries is an important sensory characteristic in determining quality of the fruit. Color is another quality factor influencing fresh market value and the suitability of the blueberries for processing (Silva et al. 2005). Blueberry texture and blueberry flavor from a highbush cultivar studied by Rosenfeld et al. (1999), were significantly affected by temperature (fruits stored at 4 and 12C) and packaging film type.

Ripeness and maturity are the key factors that influence the taste of a fruit. Ripening plays a key role in flavor development and can affect the chemical and sensory characteristics (acidity, sweetness) of fruit (Aaby et al. 2007). And, acording to Saftner et al. (2008), flavor quality characteristics best predicted overall eating quality of blueberries. Various textural and visual quality characteristics also influenced consumer assessment of overall eating quality of blueberries. Ehlenfeldt and Martin (2002) also observed that cultivars with higher firmness values often possessed a higher percentage of $V$. darrowi Camp and Vaccinium ashei Reade ancestry. Conversely, cultivars with softer than average fruit often possessed a higher percentage of lowbush (Vaccinium angustifolium Ait.) ancestry. This information may help to identify sources of breeding material for increased firmness in highbush blueberry hybrids.

Thus, in this work, chemometric tools for exploration of sensory, chemical, color and textural characteristics of four blueberry cultivars (Palmetto, Duke, Legacy and Camellia) produced in organic farming and harvested in two different years (2011 and 2013) were applied, aiming to better understand the influence of the harvest year in the textural and sensory attributes of blueberry fruit.

\section{MATERIAL AND METHODS}

\section{Samples}

The samples consisted of $1 \mathrm{~kg}$ of blueberries from Duke, Legacy (Northern Highbush Blueberries), Camellia and Palmetto (Southern Highbush Blueberries) cultivars from the BioBaga exploration (organic production and marketing of small fruits), located in Estarreja, Aveiro District, Portugal. The climate is characterized by mild winters and summers. The cultivars were planted in 2009, drip-irrigated, and the fruit collected in the month of June, in the morning at optimal ripness stage, in different years, 2011 and 2013. The blueberry fruit, in both years, were stored at $4 \mathrm{C}$ prior each analysis during 2 days, including sensory evaluation.

\section{Descriptive Sensory Analysis}

Sensory panel training and blueberry samples sensory evaluation was performed twice, in 2011 and 2013. The sensory panel, in both years, consisted of eleven participants aged from 35 to 50 years old, nine females and two males. All participants were experienced in food sensory evaluation. The panelists were nonsmokers and refrained from wearing perfume and drinking or consuming foods that could affect performance in the hour before tasting. Sessions were performed under controlled conditions of temperature $(20 \pm 2 \mathrm{C})$ and relative humidity $(60 \pm 20 \%)$ in a laboratory specifically constructed for performing sensory tests, with individual booths for each panelist. A sensory vocabulary with reference standards was developed over two sessions lasting $1.5 \mathrm{~h}$ each. From an original long list of attributes (34), a reduced list was assembled by 
TABLE 1. VOCABULARY AND REFERENCE STANDARDS USED FOR DESCRIPTIVE SENSORY ANALYSIS

\begin{tabular}{|c|c|c|}
\hline Attribute & Description & References \\
\hline Color & Intensity of blue-blueberry color & $\begin{array}{l}\text { The blue color intensity from light (intensity } 1 \text { ) to very } \\
\text { dark (intensity } 5)^{\ddagger}\end{array}$ \\
\hline Odor intensity & Overall odor intensity (ortonasal odor intensity) & Blueberry sample $\mathrm{A}^{1} \mathrm{~B}^{\dagger}$ (intensity 5 ) \\
\hline Blueberry odor* & $\begin{array}{l}\text { The expected odor associated when smelling a } \\
\text { blueberry }\end{array}$ & Blueberry sample $\mathrm{A}^{1} \mathrm{~B}^{\dagger}$ (intensity 5) \\
\hline Taste intensity & $\begin{array}{l}\text { The expected intensity of taste associated when } \\
\text { consuming a blueberry }\end{array}$ & Blueberry sample $\mathrm{A}_{1} \mathrm{~B}^{\dagger}$ (intensity 5 ) \\
\hline Sweet taste & The taste stimulated by sucrose, glucose, or fructose & $\begin{array}{l}\text { Solutions of sucrose with concentrations from } 2 \% \mathrm{w} / \mathrm{v} \\
\text { (intensity 1) to } 20 \% \mathrm{w} / \mathrm{v} \text { (intensity 5) }\end{array}$ \\
\hline Acid taste & $\begin{array}{l}\text { The taste stimulated by acids such as citric, malic, and } \\
\text { phosphoric }\end{array}$ & $\begin{array}{l}\text { Solutions of citric acid from } 0.05 \mathrm{~g} / \mathrm{L} \text { (intensity } 1 \text { ) to } \\
2.0 \mathrm{~g} / \mathrm{L} \text { (intensity 5) }\end{array}$ \\
\hline Bitter taste & $\begin{array}{l}\text { The taste stimulated by substances such as caffeine } \\
\text { and quinine sulfate }\end{array}$ & $\begin{array}{l}\text { Solutions of quinine sulfate from } 0.0003 \mathrm{~g} / \mathrm{L} \\
\text { (intensity 1) to } 0.02 \mathrm{~g} / \mathrm{L} \text { (intensity } 5 \text { ) }\end{array}$ \\
\hline Astringency & $\begin{array}{l}\text { The shrinking or puckering of the tongue surface } \\
\text { caused by substances such as tannins or alum }\end{array}$ & Solution of oenological tannin $160 \mathrm{mg} / \mathrm{L}$ (intensity 5) \\
\hline Blueberry flavor & $\begin{array}{l}\text { The expected flavor (retro-nasal evaluation) associated } \\
\text { when consuming a blueberry }\end{array}$ & Blueberry sample $\mathrm{A} 1 \mathrm{~B}^{\dagger}$ (intensity 5 ) \\
\hline Earthy flavor & $\begin{array}{l}\text { Flavor of wet earth or turf, that you feel when you } \\
\text { chew the fruit }\end{array}$ & Blueberry sample $A 1 B^{\dagger}$ (intensity 1 ) \\
\hline Firmness & The force required to fracture sample between molars & $\begin{array}{l}\text { Boiled egg white (intensity 2) and pitted olives } \\
\text { (intensity 5) }\end{array}$ \\
\hline Succulence & $\begin{array}{l}\text { The quantity of juice released by the sample when } \\
\text { chewed up to five times }\end{array}$ & $\begin{array}{l}\text { One cubic centimeter piece of water melon } \\
\text { (intensity 5) }\end{array}$ \\
\hline Crispness & $\begin{array}{l}\text { The force and sound (pitch) with which a sample } \\
\text { breaks and fractures on the first and second chew }\end{array}$ & Cracker (intensity 5) \\
\hline
\end{tabular}

*The odor was perceived as an orthonasal perception (external olfactory sense, which occurs when inhaling and allows us to detect odors in our environment) and flavor as a retro-nasal perception (migration of aromas up the nasal cavity that then stimulate organoleptic organs - olfactory nerves).

${ }^{\dagger}$ Blueberry sample A1B - three fruits from a blueberry sample in the full ripening stage and very flavorfull.

${ }^{\ddagger}$ Nominal scale for aroma flavor and textural attributes intensity scoring:

The attribute is not perceived at all 1

Doubts about the presence of the attribute 2

The attribute is clearly perceived, although it is slight 3

The attribute is clearly perceived, but the intensity is lower than the reference 4

The attribute is clearly perceived and the intensity is close or similar to the reference 5

analyzing the frequency of citations. Finally, a reduced list of thirtheen attributes was compiled by panelist general consensus (Table 1). Attribute intensities were scored on a 5 -point scale (ranging from 1 , lowest intensity, to 5 , highest intensity) according to the methodology described by Monteiro et al. (2014). The panelists were instructed to give scores to the attributes in the order they perceived them (Table 1).

For each harvest (2011 and 2013), two sessions, with 7 days apart, for each cultivar/year were performed. In each session panelists evaluated five blueberry fruit of the four cultivars. Samples were randomly presented to the panelists, coded with a three digit code number. The samples were left at room temperature for $2 \mathrm{~h}$ to obtain a temperature of about $18 \mathrm{C}$ and were presented on a white plate. Panelists were required to cleanse their palates with a bite of low-salt cracker, a sip of room temperature water and a small time lag before every sample.

\section{Instrumental Analysis}

Blueberry fruit were carried to the laboratory in coolers and stored for 1-3 days at approximatelly $4 \mathrm{C}$ until analysis. Soluble Solids (SS) and Titratable Acidity (TA) were measured from juice extracted, at ambient temperature, from two replicates of 30 berry samples in a domestic centrifugal juicer (Tefal Elea, model number ZN350C70, China), at $350 \mathrm{rpm}$ during $1 \mathrm{~min}$. SS were determined using a digital refractometer (Atago PR-101, Japan). Results are expressed as percent $\mathrm{SS}$ (wt/wt) on a fresh weight basis. TA was determined from $10 \mathrm{~mL}$ of juice diluted on $10 \mathrm{~mL}$ of distilled water and titrated with $0.1 \mathrm{~N}$ sodium hydroxide $(\mathrm{NaOH})$ to $\mathrm{pH} 8.2$ and it is reported in $\mathrm{g} / \mathrm{L}$ of malic acid. Fruit texture was profiled using a TA.XTPlus texture analyser (Stable Micro Systems, U.K.), employing a $5 \mathrm{~kg}$ loading cell and a $7.5 \mathrm{~cm}$ diameter plate probe. The maximum force $(\mathrm{N})$ applied was measured with a test speed of $1 \mathrm{~mm} / \mathrm{s}$ and a displacement of $8 \mathrm{~mm}$. Ten 
fruits of each cultivar were analyzed each year. Surface color (CIE $L^{\star} a^{\star} b^{\star}$ ) was measured using a Minolta ChromaMeter (model CR-300, Japan) calibrated with a white tile. Two measurements were done on the opposite sides of each fruit and 20 fruits of each cultivar were analyzed each year.

\section{Statistical Analysis}

Both physicochemical and sensory data were statistically tested by analysis of variance (Factorial ANOVA), and Duncan's multiple range test at 5\% significance level to compare the averages. Correlations were performed for all the studied parameters. For sensory-sensory and instrument-sensory comparisons, the average of both replicates for each cultivar and each year were used to calculate Pearson correlation coefficients which were used to model the relationships $\left(^{*}\right)$, $\left.{ }^{* *}\right)$ and $\left({ }^{* *}\right)$ indicating $0.05,0.01$ and 0.001 levels of significance, respectively.

Principal Component Analysis (PCA) was also performed. PCA is mostly used as a tool in exploratory data analysis and for making predictive models. PCA was performed by eigenvalue decomposition of data covariance (Cov-PCA - when only sensory data was analyzed and the variable scales are similar) and correlation (Corr-PCA - when sensory and chemical data were analyzed) matrix after mean centering (and normalizing) the data matrix for each attribute, accord- ing to Abdi and Williams (2010). The results of a PCA were discussed in terms of factor scores (the transformed variable values corresponding to a particular data point), and loadings (the weight by which each standardized original variable should be multiplied to get the component score).

All analysis were done using the software Statistica 2010 (StatSoft Inc 2010).

\section{RESULTS AND DISCUSSION}

\section{Instrumental and Sensory Analysis}

The analysis of Table 2 sensory data shows the berries sensory profile. Blueberry flavor, the expected flavor (retro-nasal evaluation) associated when consuming a blueberry, and crispness, the force and sound, the pitch, with which a sample breaks and fractures on the first and second chew, presents significant differences between cultivars while odor intensity (overall odor intensity - orthonasal odor intensity) is similar for all the cultivars in 2013 year, but presents significant differences between cultivars harvested in 2011, with Palmetto having a higher odor intensity value. Palmetto cultivar shows, in both years, significantly highest value for blueberry flavor attribute, and Legacy, harvested in 2011 the lowest. For the attribute crispness, year was not a significant

TABLE 2. MEAN SCORES FOR EACH PARAMETER EVALUATED AFTER SENSORY AND PHISICO-CHEMICAL ANALYSIS OF THE FOUR BLUEBERRY CULTIVARS HARVESTED IN THE YEARS 2011 AND 2013

\begin{tabular}{|c|c|c|c|c|c|c|c|c|}
\hline \multirow[b]{2}{*}{ Sensory attributes $^{\dagger}$} & \multicolumn{4}{|c|}{2011 Cultivars } & \multicolumn{4}{|c|}{2013 Cultivars } \\
\hline & Duke & Legacy & Palmetto & Camellia & Duke & Legacy & Palmetto & Camellia \\
\hline Color & $5.0^{a}$ & $5.0^{a}$ & $5.0^{a}$ & $5.0^{a}$ & $4.4^{a}$ & $4.6^{a}$ & $4.2^{a}$ & $4.9^{a}$ \\
\hline Odor intensity & $2.3^{a, b}$ & $2.3^{a, b}$ & $3.5^{b}$ & $2.0^{a, b}$ & $1.4^{\mathrm{a}}$ & $1.4^{\mathrm{a}}$ & $1.4^{\mathrm{a}}$ & $1.3^{\mathrm{a}}$ \\
\hline Blueberry odor & $2.5^{\mathrm{a}}$ & $2.2^{\mathrm{a}}$ & $3.2^{a}$ & $2.2^{\mathrm{a}}$ & $1.4^{a}$ & $1.4^{a}$ & $1.4^{a}$ & $1.3^{a}$ \\
\hline Taste intensity & $3.8^{a}$ & $3.0^{a}$ & $3.8^{\mathrm{a}}$ & $3.5^{\mathrm{a}}$ & $3.2^{a}$ & $3.1^{a}$ & $3.9^{a}$ & $3.1^{a}$ \\
\hline Sweet taste & $3.3^{a}$ & $2.8^{a}$ & $3.0^{a}$ & $3.5^{a}$ & $2.3^{a}$ & $2.8^{a}$ & $2.9^{a}$ & $2.8^{a}$ \\
\hline Acid taste & $2.8^{a}$ & $2.8^{a}$ & $2.7^{a}$ & $2.7^{a}$ & $3.2^{a}$ & $3.1^{a}$ & $3.1^{a}$ & $2.7^{a}$ \\
\hline Bitter taste & $1.2^{a}$ & $1.2^{\mathrm{a}}$ & $1.7^{\mathrm{a}}$ & $1.0^{a}$ & $1.7^{\mathrm{a}}$ & $1.4^{a}$ & $1.7^{\mathrm{a}}$ & $1.3^{a}$ \\
\hline Astringency & $1.5^{\mathrm{a}}$ & $1.7^{\mathrm{a}}$ & $1.2^{\mathrm{a}}$ & $1.2^{\mathrm{a}}$ & $1.8^{\mathrm{a}}$ & $1.7^{\mathrm{a}}$ & $1.6^{\mathrm{a}}$ & $1.6^{\mathrm{a}}$ \\
\hline Blueberry flavor & $3.3^{a . b}$ & $2.7^{a}$ & $4.2^{b}$ & $3.0^{a \cdot b}$ & $3.2^{a, b}$ & $3.4^{a, b}$ & $3.9^{b}$ & $3.2^{a, b}$ \\
\hline Earthy flavor & $0.3^{a}$ & $0.5^{a}$ & $0.8^{a}$ & $0.3^{a}$ & $1.6^{\mathrm{a}}$ & $1.4^{a}$ & $1.8^{\mathrm{a}}$ & $1.3^{\mathrm{a}}$ \\
\hline Firmness & $3.7^{a}$ & $3.3^{a}$ & $3.3^{a}$ & $3.2^{a}$ & $3.3^{a}$ & $3.2^{a}$ & $3.3^{a}$ & $3.3^{a}$ \\
\hline Succulence & $3.3^{a}$ & $3.3^{a}$ & $2.8^{a}$ & $3.0^{\mathrm{a}}$ & $3.2^{a}$ & $3.4^{a}$ & $3.2^{\mathrm{a}}$ & $3.3^{a}$ \\
\hline Crispness & $3.5^{b}$ & $2.5^{a, b}$ & $3.3^{b}$ & $2.2^{a}$ & $3.3^{b}$ & $3.3^{b}$ & $3.1^{a, b}$ & $3.3^{b}$ \\
\hline \multicolumn{9}{|l|}{ Color* } \\
\hline$L^{*}$ & $29.81^{d}$ & $27.95^{c}$ & $26.09^{b}$ & $24.22^{a}$ & $28.25^{c}$ & $27.47^{b}$ & $24.96^{a}$ & $29.01^{d}$ \\
\hline$a^{*}$ & $1.20^{a, b}$ & $1.58^{a, b}$ & $1.93^{c}$ & $0.99^{a}$ & $1.13^{a}$ & $0.91^{a}$ & $1.82^{b}$ & $1.21^{a, b}$ \\
\hline$b^{*}$ & $-1.63^{a}$ & $-1.74^{a}$ & $-1.39^{a}$ & $0.06^{b, c}$ & $-0.75^{b}$ & $-0.50^{\mathrm{b}}$ & $0.89^{c}$ & $-1.51^{a}$ \\
\hline \multicolumn{9}{|l|}{ Sugar/acid $^{\dagger}$} \\
\hline SS (\%, wt/wt) & $10.75^{a}$ & $12.08^{b}$ & $13.70^{c}$ & $12.28^{b}$ & $10.03^{a}$ & $11.30^{a, b}$ & $13.27^{c}$ & $11.57^{a, b}$ \\
\hline TA (g/L malic acid) & $7.96^{\mathrm{a}}$ & $8.74^{b}$ & $8.75^{\mathrm{b}}$ & $8.44^{b}$ & $4.75^{a}$ & $6.01^{\mathrm{b}}$ & $9.31^{\mathrm{c}}$ & $6.15^{b}$ \\
\hline $\mathrm{SS} / \mathrm{TA}$ & $1.58^{a}$ & $1.51^{a}$ & $1.58^{a}$ & $1.55^{\mathrm{a}}$ & $2.13^{b}$ & $1.89^{b}$ & $1.43^{\mathrm{a}}$ & $1.89^{b}$ \\
\hline \multicolumn{9}{|l|}{ Texture $^{+}$} \\
\hline Maximum force $(\mathrm{N})$ & $18.97^{b}$ & $13.60^{a}$ & $12.96^{a}$ & $20.36^{c}$ & $19.29^{b}$ & $13.60^{a}$ & $11.41^{a}$ & 1. b,c \\
\hline
\end{tabular}

${ }^{\dagger}$ Values with the same superscript letter do not differ significantly $(P \leq 0.05)$ for the parameter tested (Factorial ANOVA - Duncan's test). 
effect for all cultivars, with the exception of Camellia. This cultivar presented in 2011 a significantly lower value for crispness. The higher crispness in Camellia fruit, in 2013, may be linked to weather differences. The 2013 growing season had rainfall levels above average, while the 2011 had rainfall below average (Table 3). Drier conditions may led to the formation of thicker cuticles on fruits (Ehlenfeldt and Martin 2002). However, rainfall may have led to swelling of berries in response to turgor changes, which increases crispness, and this phenomenon was detected by the tasters.

The main quality indicators of blueberry fruit are color, size and shape, in terms of appearence, firmness/crispness or texture and flavor (Duarte et al. 2009). The color ranges from light blue to deep black blue depending on the cultivar and the presence of epicuticular waxes (Nunes et al. 2004). Surface color $\left(L^{*} a^{*} b^{*}\right)$, maximum force, SS, TA (expressed in malic acid), SS/TA ratio and texture (Table 2) varied among cultivars and years. Higher values of lightness $\left(L^{*}\right)$ were found in Duke cultivar in 2011 harvest (29.81) and Camellia cultivar in 2013 (29.01). Palmetto fruit showed the highest chromatic coordenate $a^{*}$ value both years and the highest $b^{*}$ in 2013. In 2011, berries from Camellia cultivar presented the highest $b^{*}$ (Table 2). In spite all these, the panel did not found any significant differences among cultivars in the atributte color, maybe because the color coordinates values were not different enough to be detected by the naked eye or because they only analyzed five fruits of each cultivar, while in the surface color (CIE $L^{\star} a^{\star} b^{\star}$ ) measurements, as reported in the material and methods section, two measurements were done on the opposite sides of each fruit and 20 fruits of each cultivar were analyzed each year.

Camellia cultivar also presented significantly higher values for texture in both years, 2011 and 2013, respectively 20.36 $\mathrm{N}$ and $19.46 \mathrm{~N}$. The quality parameters that dictated useful storage life in these cultivars are principally firmness and bruising (Conor et al. 2002), and these characteristics may vary from season to season and among cultivars (Eck 1988).

TABLE 3. SOLAR RADIATION PER MONTH (LIGHT) FOR THE MONTHS OF APRIL, MAY AND JUNE OF BOTH YEARS (2011 AND 2013)

\begin{tabular}{clrrrrr}
\hline Year & Month & $\begin{array}{r}T_{\min } \\
\text { (C) }\end{array}$ & $\begin{array}{r}T_{\max } \\
(\mathrm{C})\end{array}$ & $\begin{array}{r}\mathrm{PP}_{\text {total }} \\
\left(\mathrm{mm}^{3}\right)\end{array}$ & $\begin{array}{r}\mathrm{PP}_{\max / \text { day }} \\
\left(\mathrm{mm}^{3}\right)\end{array}$ & $\begin{array}{r}\text { Light } \\
\left(\mathrm{MJ} / \mathrm{m}^{2}\right)\end{array}$ \\
\hline \multirow{6}{*}{2011} & April & 13.5 & 22.9 & 41.1 & 4.6 & 600 \\
& May & 15.4 & 23.0 & 0.1 & 6.6 & 700 \\
& June & 15.3 & 22.8 & 0.0 & 2.3 & 750 \\
& Average & 14.7 & 22.9 & 13.7 & 4.5 & 683 \\
& April & 10.5 & 18.0 & 62.2 & 12.4 & 600 \\
& May & 10.9 & 17.8 & 37.6 & 11.5 & 750 \\
& June & 14.5 & 22.3 & 37.2 & 21.9 & 750 \\
& Average & 12.0 & 19.4 & 45.7 & 15.3 & 700 \\
\hline
\end{tabular}

Data provided by the IPMA (Instituto Português do mar e da Atmosfera).

Minimum temperature $\left(T_{\min }\right)$, maximum temperature $\left(T_{\max }\right)$, total precipitation ( $\left.\mathrm{PP}_{\text {total }}\right)$, maximum precipitation per day $\left(\mathrm{PP}_{\text {max/day }}\right)$.
Environmental factors including light, temperature and moisture have pronounced effects on fruit texture. Information on the variation in fruit texture among both seasons and locations, in pears and apples, have been reported by Luton and Holland (1986) and Knee and Smith (1989), respectively. Intensity of solar radiation also affects fruit texture as the temperature during production affects growth and development. Temperature has a direct influence on metabolism affecting cellular structure and other components which determine texture (Sams 1999). Fruit size, in general, is negatively correlated to firmness and texture. In blueberries, small fruits are firmer than larger fruits (Ballinger et al. 1973). This may be related to the fact that fruit size is determined by both cell size and cell number. Small fruits which have the same number of cells as larger fruits have a greater percentage of their volume in cell wall material. Thus, tissue density would be higher (Sams 1999). Despite all these reasons, in our study, texture of blueberry fruits has not significantly changed between the two years, which may indicate genetic factors. Although environmental factors may modify the expression of textural characters, genetic background of the plant is the major factor controlling texture (Sams 1999) and other parameters as also reported by De Wit et al. (2010) in a work with Cactus Pear and Calín-Sánchez et al. (2013) in a work with Black and White Mulberries grown in Spain. For instances, Strawberry cultivars vary greatly in their rate of softening and overall texture (Shaw et al. 1987).

Generally higher values of TA are negatively linked with the flavor and consumer acceptance (Chitarra and Chitarra 2005), but it was not the case of our study since the Palmetto cultivar showed higher values in the parameters related to the fruit sweetness, SS and TA in both harvest years and it was also the cultivar that presented higher classification for the attribute blueberry flavor (Table 2). This cultivar also presented the lowest SS/TA ratio in the 2013 harvest (1.43). Generally, all the fruits presented in 2013 had lower values for SS and TA when compared with the fruits collected in 2011. The main cause for this singularity may be the variations in the climate that occurred during the months (April to June) for fruit development. Blueberry plants start coming to life by March from their dormant stage in winter. In April, the plants reach full vigour with small fruit developing. In May, the plants have matured and the fruit is ready to harvest (Panda et al. 2011). Acording to IPMA (2015) Table 3, the period of time between April and June 2011 higher temperatures and less precipitation occurred than in the same period of 2013. Nevertheless, in the year 2013 there was, on average, an higher value of milliJoule per square metre for solar radiation (Table 3). As it was mentioned before, intensity of solar radiation also affects fruit texture as the temperature during production affects growth and plant methabolism, affecting cellular structure and other 
components which determine texture (Sams 1999). The higher precipitation that ocurred in 2013 may be the cause for lower SS and TA values in the fruits.

\section{Sensory and Textural Relationships}

A goal of our research was to better understand the relationships among sensory quality characteristics of blueberries, with the purpose of more accurately assessing the impact of the harvest year. For the parameters studied, correlations were performed using the average of both replicates for each cultivar and each year. For the four cultivars used in this study, blueberry odor was most highly correlated with odor intensity $\left(r=0.98^{* *}\right)$ and correlated with sweet taste $\left(r=0.55^{\star *}\right)$. Blueberry flavor was also correlated with taste intensity $\left(r=0.71^{\star *}\right)$ and bitter taste $\left(r=0.73^{\star * *}\right)$. These results suggest that aroma (odor) and flavor-related characteristics are, in a way, related to sweet and bitter sensations in the mouth. The bitterness may also be present in ripe fruit namely in the fruit skin.

Blueberry mechanical properties can be mesured by nondestructive and noncontact measurement tools such as hyperspectral imaging system, instead of conventional destructive methods such as sensory evaluation (Hua et al. 2015), however, sensory evaluation also gave a prediction about this characteristic in blueberry fruit, being a much less expensive way to do it. Sensory textural scores for firmness are correlated with blueberry crispness $\left(r=0.56^{\star *}\right)$. Earthy flavor, a descriptor that aims to measure the unpleasant sensation of wet earth or turf, felt when chewing the fruit, shows negative correlations blueberry odor $\left(r=-0.72^{\star \star}\right)$.

When we study the correlations between sensory attributes and analytical/textural data we verify that the earthy flavor is highly correlated with SS/TA ratio $\left(r=0.74^{\star * *}\right)$ but shows a negative correlation with the titratable acidity - TA $\left(r=-0.76^{* *}\right)$. The SS content is correlated with the fruit odor intensity $\left(r=0.64^{\star *}\right)$, blueberry odor $\left(r=0.60^{\star *}\right)$ and sweet taste $\left(r=0.51^{\star *}\right)$. Succulence, the quantity of juice released by the sample when chewed up to five times is also correlated with maximum force $\left(r=0.54^{\star *}\right)$.

\section{PCA Data Analysis and Descriptors Weight for Blueberry Characterization}

The cov-PCA data (covariance - PCA) allowed distinguishing the weight of each descriptor to the similarities of the studied blueberry fruit harvested in 2011 and 2013. In Fig. $1 \mathrm{~A}$, the first two factorial axes (PC1 and PC2) represent $83.07 \%$ of the total variance. In a PCA analysis, if both the first three components accumulate a relatively high percentage of the total variation, in general above $70 \%$, they satisfactorily explain the variability among the samples tested (Mardia et al. 1979). In this study, it appears that the accumulated percentage $83.07 \%$ satisfactorily accounts for the variability found in the blueberry fruit evaluated. In fact, this value is higher than the value cited by Rosenfeld et al. (1999) and Saftner et al. (2008) in similar analysis.

In the spatial projection of Fig. 1A, it is possible to visualize the distribution of the samples evaluated sensorially and the sensory descriptors associated. In this projection, cultivars are distributed into three groups. One group, blueberry
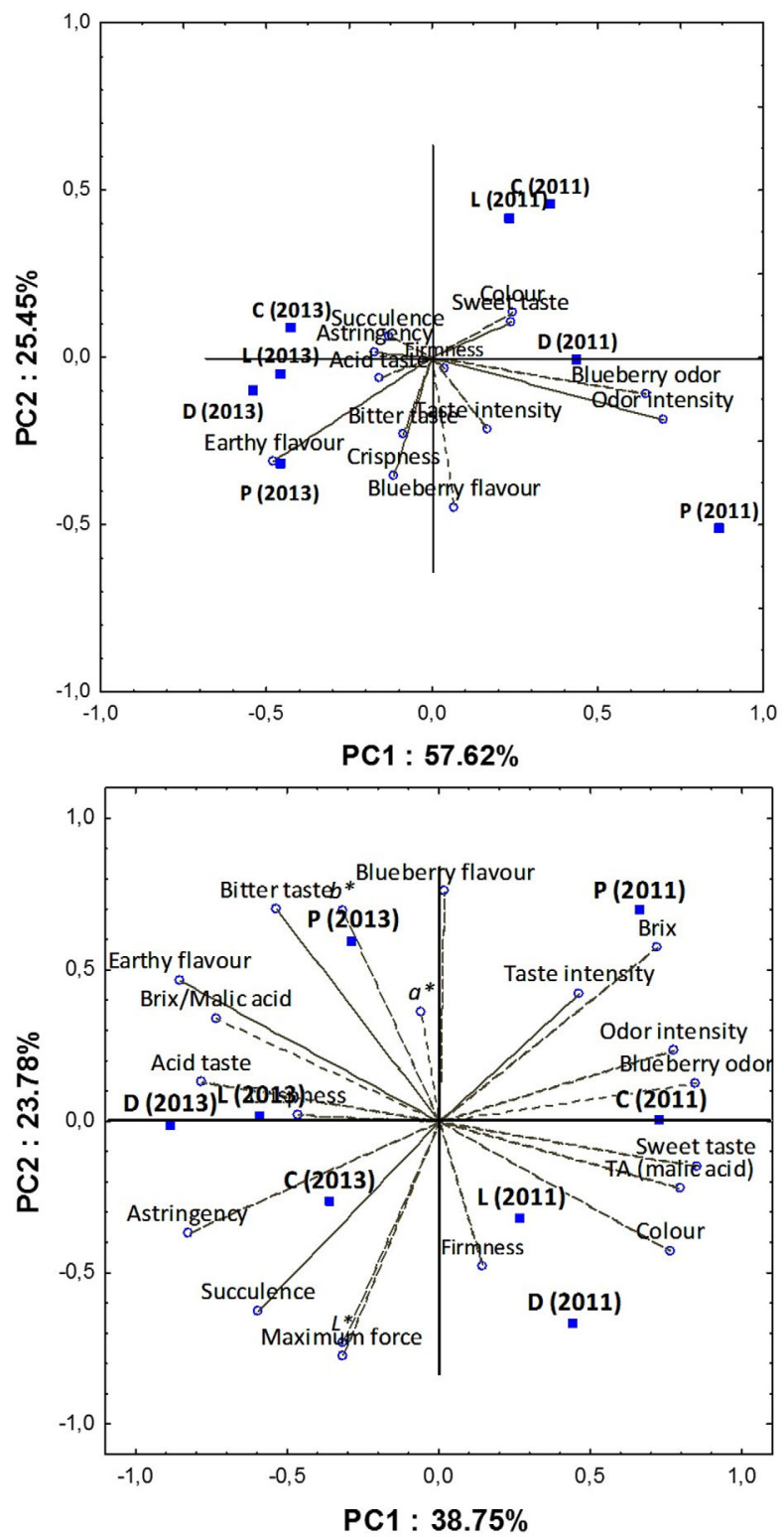

FIG. 1. (A) PRINCIPAL COMPONENT ANALYSIS (COV-PCA) OF SENSORY DATA; (B) PRINCIPAL COMPONENT ANALYSIS (CORR-PCA) WITH FACTOR 1 AND FACTOR 2 OBTAINED BY ANALYSIS OF SENSORY AND ANALYTICAL DATA OF FOUR BLUEBERRY CULTIVARS HARVESTED IN 2011 AND 2013 
samples from Camellia, Legacy and Duke cultivars, harvested in 2011, is located into PC1 and PC2 positive coordinates (right-upper PCA quadrant). The sensory descriptors that seem to contribute to the formation of this group are: color and sweetness (Table 4). The Palmetto cultivar (2011) is alone (low-right PCA quadrant) and distinguished from the others by the descriptors: blueberry odor, odor intensity, taste intensity and blueberry flavor. In PC1, the four blueberry cultivars harvested in 2013 have negative coordinates. Earthy flavor, bitter taste, crispness and acid taste (Table 4) seem to be the descriptors that more contribute to the positioning of Legacy Palmetto and Duke cultivars in 2013 harvest while Camellia, harvest in the same year, is characterized by its succulence and astringency (Table 4).

A chemometric analysis was performed integrating the sensory and the analytical data (Fig. 1B). The covariance matrix is used when the variable scales are similar and the correlation matrix when variables are on different scales. The PCA based on the correlation matrix standardizes the data. Therefore, this analysis was performed using a correlation matrix (Corr-PCA). In this analysis, the first two factorial axes (PC1 and PC2) represent $62.53 \%$ of the total variance.

In the spatial projection of Fig. $1 \mathrm{~B}$, it is possible to visualize the distribution of the samples evaluated and the associated parameters. In this projection the cultivars are distributed into two groups. One group, blueberry samples harvested in 2013, is located into left two PCA quadrants. The sensory and the analytical parameters that seem to contribute to the formation of this group are, according to Table 5, the negative parameters in PC1: acid taste, astringency, earthy flavor, crispness and SS/TA; and the negative and positive parameters in PC2: bitter taste, blue-

TABLE 4. FACTOR COORDINATES OF THE VARIABLES, BASED ON COVARIANCE OF THE THIRTHEEN SENSORY ATTRIBUTES

\begin{tabular}{lrr}
\hline Parameters & PC 1 & \multicolumn{1}{c}{ PC 2 } \\
\hline Color & $\mathbf{0 . 2 4 2 2 1 0}$ & 0.134186 \\
Odor intensity & $\mathbf{0 . 6 9 6 3 2 7}$ & -0.185220 \\
Blueberry odor & $\mathbf{0 . 6 4 4 4 7 0}$ & -0.109353 \\
Taste intensity & 0.169101 & $-\mathbf{0 . 2 1 3 1 1 6}$ \\
Sweet taste & $\mathbf{0 . 2 3 7 8 8 0}$ & 0.107750 \\
Acid taste & -0.159233 & -0.063078 \\
Bitter taste & -0.086809 & $-\mathbf{0 . 2 3 1 2 3 8}$ \\
Astringency & -0.171520 & 0.016751 \\
Blueberry flavor & 0.066351 & $-\mathbf{0 . 4 4 7 7 0 0}$ \\
Earthy flavor & $-\mathbf{0 . 4 7 7 1 3 3}$ & -0.311030 \\
Firmness & 0.036650 & -0.031195 \\
Succulence & -0.130631 & 0.061283 \\
Crispness & -0.115077 & $-\mathbf{0 . 3 5 2 4 7 1}$ \\
\hline PCA was peformed by & &
\end{tabular}

PCA was performed by eigenvalue decomposition of data covariance of the thirteen sensory attributes. Numbers in bold indicate the position of each attribute according PC1 or PC2.
TABLE 5. FACTOR COORDINATES OF THE VARIABLES, BASED ON CORRELATION OF THE THIRTHEEN SENSORY ATTRIBUTES AND SEVEN PHYSICAL-CHEMICAL PARAMETERS

\begin{tabular}{lrr}
\hline Parameters & PC 1 & \multicolumn{1}{c}{ PC 2 } \\
\hline Color & $\mathbf{0 . 7 6 4 3 2 8}$ & -0.428984 \\
Odor intensity & $\mathbf{0 . 7 7 6 1 8 2}$ & 0.233158 \\
Blueberry odor & $\mathbf{0 . 8 5 0 0 5 8}$ & 0.125639 \\
Taste intensity & $\mathbf{0 . 4 6 5 3 7 7}$ & 0.422011 \\
Sweet taste & $\mathbf{0 . 8 5 1 0 9 7}$ & -0.147899 \\
Acid taste & $-\mathbf{0 . 7 8 0 8 0 6}$ & 0.126714 \\
Bitter taste & -0.532833 & $\mathbf{0 . 6 9 9 8 1 7}$ \\
Astringency & $-\mathbf{0 . 8 2 7 1 4 3}$ & -0.368234 \\
Blueberry flavor & 0.020633 & $\mathbf{0 . 7 5 7 6 7 6}$ \\
Earthy flavor & $-\mathbf{0 . 8 5 5 3 1 5}$ & 0.464377 \\
Firmness & 0.147068 & $-\mathbf{0 . 4 8 1 3 9 3}$ \\
Succulence & -0.592776 & $-\mathbf{0 . 6 2 7 4 0 4}$ \\
Crispness & $-\mathbf{0 . 4 6 4 0 8 0}$ & 0.019760 \\
L $^{*}$ & -0.317945 & $-\mathbf{0 . 7 3 2 7 9 2}$ \\
$a^{*}$ & -0.054968 & $\mathbf{0 . 3 6 0 8 1 9}$ \\
b $^{*}$ & -0.317696 & $\mathbf{0 . 6 9 4 5 3 6}$ \\
${ }^{\circ}$ Brix or SS & $\mathbf{0 . 7 2 2 5 0 4}$ & 0.571649 \\
TA (malic acid) & $\mathbf{0 . 7 9 7 0 9 0}$ & -0.221510 \\
${ }^{\circ}$ Brix/Malic acid (SS/TA) & $-\mathbf{0 . 7 3 4 0 9 0}$ & 0.339600 \\
Maximum force & -0.317517 & $-\mathbf{0 . 7 7 7 2 4 4}$ \\
\hline
\end{tabular}

PCA was performed by eigenvalue decomposition of data correlation of the thirteen sensory attributes and seven physical-chemical parameters. Numbers in bold indicate the position of each attribute according PC1 or PC2.

berry flavor, firmness, succulence, $L^{*}, a^{*}, b^{*}$ coordinates, and maximum force.

The other group is formed by the samples harvested in 2011, and it is located into the right two PCA quadrants (Fig. 1B). The sensory and the analytical parameters that seem to contribute to the formation of this group are, according to Table 5, the positive parameters in $\mathrm{PC1}$ : color, odor intensity, blueberry odor, taste intensity, sweet taste, ${ }^{\circ}$ Brix and TA; and the negative and positive parameters in PC2: bitter taste, blueberry flavor, firmness, succulence, $L^{*}, a^{*}, b^{*}$, and maximum force.

\section{CONCLUSIONS}

In this work, chemometric tools for exploration of sensory, chemical, color and textural characteristics of four blueberry cultivars (Palmetto, Duke, Legacy and Camellia) produced in organic farming and harvested in two different years (2011 and 2013) were applied, aiming to better understand the influence of the harvest year in the textural and sensory attributes of these blueberry fruits.

Surface color, maximum force, SS, TA and SS/TA ratio varied among cultivars and years and, in general, the 2013 fruit had lower values for SS and TA when compared with the fruits collected in 2011 and PCA analysis showed that 
the cultivars were grouped by the harvest year. This means that the weather has a significant impact on the overall fruits quality namely in characteristics such us acid taste, astringency, earthy flavor, crispness and SS/TA, more relevant for cultivars in 2013 harvest year and color, odor intensity, blueberry odor, taste intensity, sweet taste, SS/TA, more pertinent for cultivars in 2011 harvest year independently of NHB or SHB cultivars.

Camellia and Duke cultivars presented significantly higher values for texture in both years. Moreover, this parameter for Camellia, has not significantly changed between the 2 years, explained by robustness of genetic factors to the environment. In fact, environmental factors may modify the expression of textural characters, but, genetic background seems to be the major factor controlling texture. Conversely, Palmetto and Duke cultivars did not change significantly between the 2 years for the attribute crispness as they present similar values for this parameter in both years.

Bearing in mind all the parameters evaluated, and independently of their origin (NHB blueberries or SHB blueberries), Duke and Palmetto seem to be more suitable for fresh market consumption, since, as it was mentioned before, the "eating quality" of blueberries has a much higher correlation to consumer acceptance and indication of "blueberry-like flavor intensity" than the traditional measures of sweetness, acidity or sugar/acid ratios.

Camellia, a cultivar where the atributte crispness, seems to be weather dependent, and Legacy a cultivar with less odor and flavor, seems to be more suitable for processing into products such juice and jam.

\section{ACKNOWLEDGMENTS}

This work was partially sponsored by the Institute for Biotechnology and Bioengineering, Centre of Genomic and Biotechnology (IBB/CGB-UTAD), by the Centre for the Research and Technology of Agro-Environmental and Biological Science (CITAB), by European Union Funds (FEDER/COMPETE - Operational Competitiveness Programme), by national funds (FCT - Portuguese Foundation for Science and Technology) under the project FCOMP-010124-FEDER-022692 and by Project INNOFOOD - INNovation in the FOOD sector through the valorization of food and agro-food by-products - NORTE-07-0124-FEDER0000029, financed by the North Portugal Regional Operational Programme (ON.2 - O Novo Norte) under the National Strategic Reference Framework (QREN), through FEDER, as well as by PIDDAC through FCT/MEC. The authors would like to thank the entire tasting panel that participated in this work (Ana Alice Santos, António Inês, Berta Gonçalves, Carla Amaral, Edna Cabecinha, Eunice Bacelar,
Fernanda Cosme, Fernando Nunes, Paula Ribeiro, Rosário Anjos and Teresa Pinto).

\section{REFERENCES}

AABY, K., WROLSTAD, R.E., EKEBERG, D. and SKREDE, G. 2007. Polyphenol composition and antioxidant activity in strawberry purees; impact of achene level and storage. J. Agric. Food Chem. 55, 5156-5166.

ABDI, H. and WILLIAMS, L.J. 2010. Principal component analysis. Wiley Interdiscip. Rev. Comput. Stat. 2, 433-459.

BALLINGER, W.E., KUSHMANN, L.J. and HAMANN, D.D. 1973. Factors affecting the firmness of highbush blueberries. J. Am. Soc. Hortic. Sci. 98, 583-587.

CALÍN-SÁNCHEZ, A., MARTÍNEZ-NICOLÁS, J.J., MUNERAPICAZO, S., CARBONELL-BARRACHINA, A.A., LEGU, P. and HERNÁNDEZ, F. 2013. Bioactive compounds and sensory quality of black and white mulberries grown in Spain. Plant Foods Hum. Nutr. 68(4), 370-377.

CHITARRA, M.I.F. and CHITARRA, A.B. 2005. Post-Harvest Fruits and Vegetables: Physiology and Handling, UFLA, Lavras, Brazil.

CONNOR, A.M., LUBY, J.J., HANCOCK, J.F., BERKHEIMER, S. and HANSON, E.J. 2002. Changes in fruit antioxidant activity among blueberry cultivars during cold-temperature storage. J. Agric. Food Chem. 50, 893-898.

DE WIT, M., NEL, P., OSTHOFF, G. and LABUSCHAGNE, M.T. 2010. The effect of variety and location on cactus pear (Opuntia ficus-indica) fruit quality. Plant Foods Hum. Nutr. 65(2), 136-145.

DUARTE, C., GUERRA, M., DANIEL, P., CAMELO, A.L. and YOMMI, A. 2009. Quality changes of highbush blueberries fruit stored in CA with different $\mathrm{CO}_{2}$ levels. J. Food Sci. 74, S154-S159.

ECK, P. 1988. Fruit Development. Blueberry Science, Rutgers University Press, New Brunswick, NJ.

EHLENFELDT, M.K. and MARTIN, R.B. JR. 2002. A survey of fruit firmness in highbush blueberry and species-introgressed blueberry cultivars. HortScience 37, 386-389.

HUA, M-H., DONG, Q-L., LIU, B-L,. OPARA, U.L. and CHEN, L. 2015. Estimating blueberry mechanical properties based on random frog selected hyperspectral data. Postharvest Biol. Technol. 106, 1-10.

IPMA. 2015. Instituto Portugês do Mar e da atmosfera, Lisboa. https://www.ipma.pt/pt/index.html

KNEE, M. and SMITH, S.M. 1989. Variation in quality of apple fruits stored after harvest on different dates. J. Hortic. Sci. 64, 413-419.

LITZ, R.E. 2005. Biotechnology of Fruit and Nut Crops. Google Books - Biotechnology in Agriculture Series, vol 29. CAB Publishing, CAB International, Wallingford, UK.

LUTON, M.T. and HOLLAND, D.A. 1986. The effects of preharvest factors on the quality of stored Conference pears 1 . Effects of orchard factors. J. Hortic. Sci. 61, 23-32.

MARDIA, L.V., KENI, J.T. and BIBBY, J.M. 1979. Multivariate Analysis, Academic Press, London. 
MATIACEVICH, S., COFRÉ, D.C., SILVA, P., ENRIONE, J. and OSORIO, F. 2013. Quality parameters of six cultivars of blueberry using computer vision. Int. J. Food Sci. 2013, 8.

MELLANO, M.G., CARLI, C., FOLINI, L., DRAICCHIO, P. and BECCARO, G. 2009. Training of two groups of tasters for the creation of sensory profiles of highbush blueberry cultivars grown in Northern Italy. Acta Hortic. 810, 835-840.

MONTEIRO, B., VILELA, A. and CORREIA, E. 2014. Sensory profile of pink port wines: Development of a flavour lexicon. Flavour Fragr. J. 29, 50-58.

NESMITH, S.D. and DRAPER, A.D. 2006. 'Camellia': also a new midseason southern highbush blueberry cultivar. HortScience 41, 512-513.

NESMITH, S.D., DRAPER, A.D. and SPIERS, J.M. 2004. 'Palmetto': A New Southern Highbush Blueberry Cultivar. HortScience 39, 1774-1775.

NUNES, M.C., EMON, J.P. and BRECHT, J.K. 2004. Quality curves for Highbush blueberries as a function of the storage temperature. Proceedings of the $9^{\text {th }}$ North American Blueberry Research and Extension Workers Conference; and In Small Fruits Review pp. 423-438, Food Product Press, Haworth Press.

OLIVEIRA, P.B. and FONSECA, L.P. 2010. Small Fruit Production - Research Trials. Folhas de Divulgação HEF 1, 1-31.

PALLAS, L.A., PEGG, R.B. and KERR, W.L. 2013. Quality factors, antioxidant activity, and sensory properties of jet-tube dried rabbiteye blueberries. J. Sci. Food Agric. 93, 1887-1897.

PANDA, S.S., MARTIN, J. and HOOGENBOOM, G. 2011. Blueberry crop growth analysis using climatologic factors and multi-temporal remotely sensed imagery. Proceedings of the
2011 Georgia Water Resources Conference, April 11-13, University of Georgia.

PAREDES-LÓPEZ, O., CERVANTES-CEJA, M.L., VIGNA-PÉREZ, M. and HERNÁNDEZ-PÉREZ, T. 2010. Berries: Improving human health and healthy aging, and promoting quality life - a review. Plant Foods Hum. Nutr. 65, 299-308.

ROSENFELD, H.J., MEBERG, K.R., HAFFNER, K. and SUNDELL, H.A. 1999. MAP of highbush blueberries: Sensory quality in relation to storage temperature, film type, and initial high oxygen atmosphere. Postharvest Biol. Technol. 16, 27-36.

SAFTNER, R., POLASHOCK, J., EHLENFELDT, M. and VINYARD, B. 2008. Instrumental and sensory quality characteristics of blueberry fruit from twelve cultivars. Postharvest Biol. Technol. 49, 19-26.

SAMS, C.E. 1999. Preharvest factors affecting postharvest texture. Postharvest Biol. Technol. 15, 249-254.

SHAW, D.V., BRINGHURST, R.S. and VOTH, V. 1987. Genetic variation for quality traits in an advanced-cycle breeding population of strawberries. J. Am. Soc. Hortic. Sci. 112, 699-702.

SIDEL, J.L. and STONE, H. 1993. The role of sensory evaluation in the food industry. Food Qual. Prefer. 4, 65-73.

SILVA, J.L., MARROQUIN, E., MATTA, F.B., GARNER, J.R. and STOJANOVIC, J.O. 2005. Physicochemical, carbohydrate and sensory characteristics of highbush and rabbiteye blueberry cultivars. J. Sci. Food Agric. 85, 1815-1821.

STAT SOFT, INC. 2010. Electronic Statistics Textbook. Tulsa, OK: StatSoft. WEB: http://www.statsoft.com/textbook/. 